\title{
Short-term memory in vision: A partial replication of the Averbach and Coriell study'
}

\author{
M. S. Mayzner, E. L. Abrevaya, R. E. Frey, H. G. Kaufman and K. M. Sehoenberg \\ NEW YORK UNIVERSITY
}

\begin{abstract}
A partial replication of the Averbach and Coriell study on short-term memory in vision was carried out employing six Ss, with a stimulus array consisting of a $2 \times 6$ matrix of letters. Three delay intervals of 50 , 100 , and $150 \mathrm{~ms}$. between letter matrix and bar marker were employed. The results failed to confirm the findings of Averbach and Coriell and showed that delay interval over the range examined had no effect on recognition accuracy.
\end{abstract}

\section{Problem}

In a recent paper Averbach \& Coriell (1961) report on a group of experiments designed to demonstrate a mechanism of short-term storage in the visual system, and the decay, readout, and erasure of information in such a visual storage system. Since their model of visual storage is based on experimental findings employing only three Ss, it was felt desirable to replicate in part, at least, some of their procedures, and the present report is a preliminary step in this direction.

Specifically, Averbach and Coriell presented a $2 \times 8$ matrix of letters and followed this array at varying delay intervals with a bar marker above or below one of the letters in the matrix. Their findings clearly showed that recognition accuracy of the letter indicated by the bar marker dropped from approximately 75 to $30 \%$, when the bar marker was delayed from zero to $200 \mathrm{~ms}$. The present study employs a $2 \times 6$ letter matrix and three delay intervals, 50, 100, and 150 $\mathrm{ms}$., to assess the effect of delay interval on recognition accuracy.

\section{Method}

A three field tachistoscope (Scientific Prototype, Model GA) was used to present the stimulus arrays. Each aray consisted of a $2 \times 6$ letter matrix presented on a $5 \times 7$-in card and viewed at a distance of 44 in. Capital letters, consisting of the 20 consonants and " $y$, , $5 / 16$ in high were used. The $2 \times 6$ matrix field was $2.5 \times 1$ in. Each of six different Ss was tested 96 times, at each of three different delay intervals, 50, 100 , and $150 \mathrm{~ms}$, , between letter matrix and bar marker, on three different days, for a total of 288 trials per S. Twenty-four different arrays, each consisting of two rows of six randomly chosen letters, were presented four times to make up the 96 trials for each of the three testing sessions. The bar marker appeared with each of the 12 positions in the $2 \times 6$ letter matrix eight times, but its sequence of appearance was randomized. The letter matrix always appeared for $80 \mathrm{~ms}$. followed by a bar marker which also appeared for

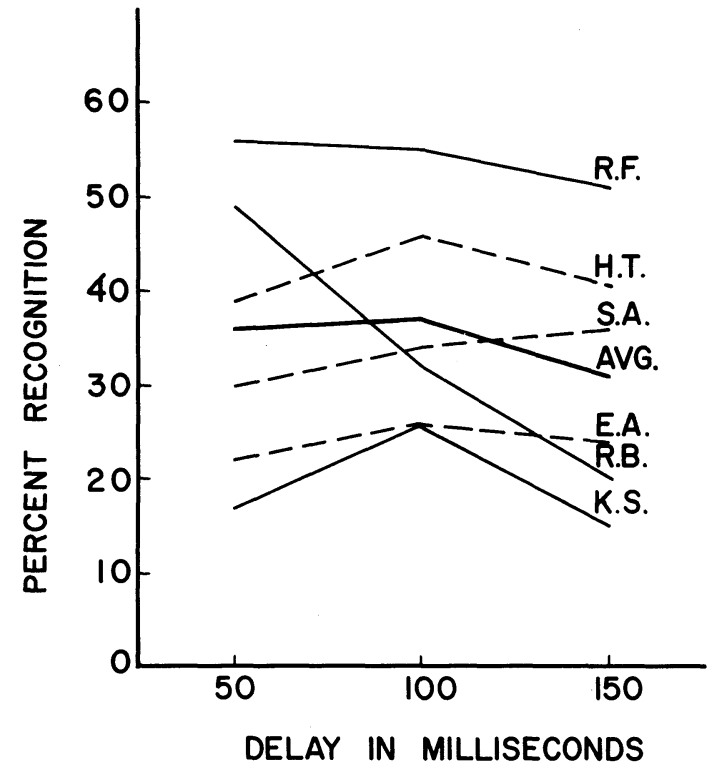

Fig. 1. Percent correct letter recognitions as a function of delay interval between letter matrix and bar marker.

$80 \mathrm{~ms}$. , at one of the three delay intervals, i. e., 50, 100 , or $150 \mathrm{~ms}$.

\section{Results}

The results for the six Ss are given in Fig. 1, which shows recognition accuracy (i. e., percent correct, corrected for chance using the formula suggested by Averbach and Coriell) as a function of the delay interval between the letter matrix and the bar marker. Examination of Fig. 1 shows no systematic effect on recognition accuracy as a function of delay interval and in fact, when the data for the six Ss are averaged the resulting function is essentially flat, leading to the conclusion that delay interval, over the range examined, has no effect on recognition accuracy.

\section{Discussion}

The results of the present study are in marked contrast to those found in the Averbach and Coriell experiment. We find no evidence of a systematic drop in recognition accuracy for increasing delay intervals, as found by Averbach and Coriell. However, our results are in marked agreement with a study by Eriksen \& Steffy 2 (in press), in which no drop in recognition accuracy occurred as a function of delay interval. Further, another recent study by Eriksen \& Collins (1964) failed to find any evidence for an erasure process of the type described by Averbach and Coriell. On the basis then of 
these conflicting findings it would appear premature to assume the existence of a short-term visual storage mechanism, into which information may be read, stored, and subsequently erased, until considerably further research is carried out.

\section{References}

AVERBACH, E., \& CORIELL, A. S. Short-term memory in vision. Bell Syst. tech. J., 1961, 40, 309-328.

ERIKSEN, C. W., \& COLLINS, J. F. Backward masking in vision. Psychon. Sci., 1964, 1, 101-102.
ERIKSEN, C. W., \& STEFFY, R. A. Short-term memory and retroactive interference in visual perception. J. exp. Psychol., in press.

\section{Notes}

1. This study was performed by the four junior authors as part of a class project in a graduate Research Methods course given by the senior author. 2 . The authors would like to express their deep appreciation to Dr. C. W. Eriksen who made available to them a pre-publication draft of this article.

\section{Sex differences in learning}

\section{Frances B. Eisenman and Russell Eisenman}

UNIVERSITY OF GEORGIA

\begin{abstract}
Archer (1960) found some consonant-vowel-consonant trigrams more meaningful to males, some more so to females, and others neutral in meaningfulness. In an experiment, Archer, Cejka, \& Thompson (1961) found both males and females learned the male list quickest. The present study was a replication of the Archer, Cejka, and Thompson study, and while the results of our study were negative, the trends were in the predicted direction.
\end{abstract}

In a monograph published by Archer (1960) it is revealed that of all possible consonant-vowel-consonant trigrams, some are more meaningful to males, some are more meaningful to females, and others are neutral in meaningfulness. Since speed of learning was expected to be related to meaningfulness, Archer et al. (1961) hypothesized that males would learn the socalled male list quickest, and females the so-called female list. Their study provided only partial support for this hypothesis, both males and females learned the male list significantly faster. The present study was performed as a partial replication.

Archer et al. (1961) had a male experimenter test six males and six females; and, a female experimenter likewise tested six males and six females. They found that women learned faster as a result of being tested by a male experimenter. Consequently, our replication employed only a female experimenter.

The earlier study used psychology students, and presented the stimuli on a strip film projector. Our

Table 1. Mean Number of Trials Required for Male and Female Ss to Learn Each List

Male List Female List Neutral List

$\begin{array}{rrrr}\text { Mean } & 16.17 & 18.83 & 16.67 \\ \text { Males } \begin{array}{r}\text { S. D. } \\ \text { Mean }\end{array} & 5.08 & 6.72 & 6.62 \\ \begin{array}{c}\text { Females } \\ \text { S. D. }\end{array} & 8.94 & 6.917 & 12.50 \\ \end{array}$

study employed a memory drum, so we used nonpsychology students who were unacquainted with this apparatus. In all other respects a faithful replication was attempted.

The results with our twelve undergraduate subjects are shown in Table 1 . Our replication does not support the earlier study, since both inspection of the data visually and via $t$ tests show not a single significant difference.

There are, however, some interesting trends. As in the previous study, the results are more clear-cut with males, since they did learn the male list fastest, and the female list slowest, even though the differences are small. With the females, as in the earlier investigation, their results deviate more than the males from the predicted direction. Our female undergraduates learned the neutral list in the fewest number of trials.

If the neutral list is ignored, the results with the females are congruent with the results we obtained with males: both learn their own-sex list in the fewest trials, and take more trials to learn the oppositesex list.

While this study does not clearly support the earlier investigation, the fact that the trends are mostly in the predicted directions can be taken as tentative support. Further, it again appears that female subjects were more deviant from the predicted hypothesis, even though our replication omitted the male experimenter which had affected the results of the previous research.

This present study serves to point up how important it is to consider the sex of the subjects. Who knows how much earlier research produced negative or misleading results solely because of a failure to consider the different results which the two sexes may have yielded.

\section{References}

ARCHER, E. J. A re-evaluation of the meaningfulness of all possible CVC trigrams. Psychol. Monogr., 1960, 74, No. 10 (Whole No. 497).

ARCHER, E. J., CEJKA, J. E., \& THOMPSON, C. P. Serial-trigram learning as a function of differential meaningfulness and sex of subjects and experimenters. Canad. J. Psychol., 1961, 15, 148-153. 